\title{
Flower Color Diversity Revealed by Differential Expression of Flavonoid Biosynthetic Genes in Sacred Lotus
}

\author{
Yanjie Wang', Yeqing Chen ${ }^{1}$, Man Yuan, Zeyun Xue, Qijiang Jin, and Yingchun Xu' \\ College of Horticulture, Nanjing Agricultural University, Nanjing 210095, China
}

\begin{abstract}
Additional INDex words. Nelumbo nucifera, anthocyanin, flower coloration, isolation, gene expression
Abstract. Sacred lotus (Nelumbo nucifera) is an important aquatic ornamental plant which contains several diverse flower colors, but the underlying mechanisms of its flower coloration remain unclear. In this study, seven complementary DNA (cDNA) clones of genes involved in flavonoid biosynthesis, including chalcone synthase $(C H S)$, chalcone isomerase (CHI), flavanone 3-hydroxylase (F3H), flavonoid 3' -hydroxylase (F3'H), flavonoid 3', $5^{\prime}$ hydroxylase $\left(F^{\prime} 5^{\prime} H\right)$, dihydroflavonol 4-reductase (DFR), and anthocyanidin synthase (ANS), were isolated and characterized. Moreover, expression patterns of these seven genes and pigment profiles were investigated across four $N$. nucifera cultivars with different flower colors: Zhongguohongbeijing [ZGH (red)], Xinghuafen [XHF (pink)], Molingqiuse [MLQS (yellow)], and Zhufengcuiying [ZFCY (white)]. Real-time quantitative polymerase chain reaction (qRT-PCR) analysis showed that during flower development, transcripts of early biosynthetic genes ( $\mathrm{NnCHS}, \mathrm{NnCHI}$, and $\mathrm{NnF3H}$ ) were abundant at the early stage; noticeably, highest expression of $\mathrm{NnCHI}$ in MLQS probably induced abundant anthoxanthin synthesis and displayed yellow. Expression of late biosynthetic genes, especially $N n D F R$ and $N n A N S$, was generally consistent with change patterns of anthocyanins in ZGH and XHF, but $N n F 3^{\prime} H$ was barely detectable in the pink cultivars. Meanwhile, negligible expression of $N n D F R$ and $N n A N S$ was detected in MLQS and ZFCY, respectively, which blocked their colored anthocyanin biosynthesis. Spatial expression analysis revealed that most flavonoid biosynthetic genes were highly expressed in floral tissues, rather than leaves. These results suggest that in $N$. nucifera cultivars with different flower colors, flavonoid biosynthesis is differentially regulated by the expression of these flavonoid biosynthetic genes, among which, $N n C H I, N n F 3^{\prime} H, N n D F R$, and $N n A N S$ are supposed to be critical for pigment accumulation, and therefore, affect different flower coloration.
\end{abstract}

Sacred lotus is a famous perennial aquatic plant around the world, and widely used as an ornamental flower for water features in summer. It belongs to the family Nelumbonaceae, which consists of one genus, Nelumbo, with only two species, N. nucifera and Nelumbo lutea (Wang and Zhang, 2005). Although the two species differ morphologically and genetically, there is no reproductive barrier between them, and more than 800 cultivars have been created by natural and artificial hybridization (Zhang, 2011). These cultivars possess several attractive flower colors including red, pink, white, yellow, and versicolor, but compared with other ornamental plants, the lotus flower color is not rich in diversity yet. Flower color has been regarded as a primary ornamental characteristic that determines the ornamental merit and landscaping application value. Therefore, breeding much more novel flower color cultivars is one of the most important breeding objectives in $N$. nucifera, and understanding genetic mechanisms of its petal coloration is a key to successful breeding.

Flower coloration is due to the accumulation of pigments within epidermal cells, including flavonoids, which include

\footnotetext{
Received for publication 14 June 2016. Accepted for publication 21 Sept. 2016. This work was financially supported by the Open Fund of Key Laboratory for Genetic Improvement of Ornamental Plants in Jiangxi (no. 2013-KLB-03), the China Postdoctoral Science Foundation funded project (no. 2014M561674), the National Natural Science Foundation of China (no. 31400600), and the Funding of Agricultural Science and Technology Innovation in Jiangsu [no. CX(15)1030].

We thank Yuesheng Ding and Nanjing Yileen Garden Co., Ltd. for providing flower lotus cultivars.

${ }^{1}$ These authors contributed equally to this work

${ }^{2}$ Corresponding author. E-mail: xyc@njau.edu.cn.
}

chalcones, anthoxanthins (flavones and flavonols), and anthocyanins (Qi, 1989). Among them, anthocyanins have been implicated as the major coloring factors in various species (Grotewold, 2006; Tanaka et al., 2005; Zhao and Tao, 2015). In N. nucifera, chemical constituents of flower color have been systematically studied. Yang et al. (2009) identified five major anthocyanins, including delphinidin 3-O-glucoside (Dp3G), cyanidin 3-O-glucoside (Cy3G), petunidin 3-O-glucoside $(\mathrm{Pt} 3 \mathrm{G})$, peonidin 3-O-glucoside $(\mathrm{Pn} 3 \mathrm{G})$, and malvidin 3-Oglucoside $(\mathrm{Mv} 3 \mathrm{G})$, and 10 flavonols in six cultivars of $N$. nucifera. But another major aglycon for anthocyanin named pelargonidin was not detected. Furthermore, Deng et al. (2013) assessed the composition and content of flavonoids across 108 cultivars of $N$. nucifera with red, pink, yellow, white, and pied petal colors. Five aforementioned anthocyanins except pelargonidin were found in both red and pink cultivars, with much less cyanidin derivatives (Cy3G and Pn $3 \mathrm{G})$ in the pink groups, whereas 14 anthoxanthins were detected and quantified in all cultivars. All the information has provided physiological and biochemical basis to study molecular mechanisms underlying flower color formation and diversity in $N$. nucifera.

Flavonoid formation and accumulation are derived from the flavonoid biosynthetic pathway, which has been well characterized in model species Antirrhinum majus, Petunia $\times$ hybrida, and Arabidopsis thaliana (Grotewold, 2006; Nishihara and Nakatsuka, 2011; Tanaka et al., 2008; Winkel-Shirley, 2001). The putative flavonoid biosynthetic pathway without pelargonidin-based anthocyanins in N. nucifera is illustrated in Fig. 1. In brief, the first committed step for flavonoid synthesis is the formation of chalcone catalyzed by chalcone synthase (CHS), which is required for the synthesis of all flavonoids. Chalcone 
isomerase $(\mathrm{CHI})$ is the enzyme that catalyzes the isomerization of chalcone to form colorless naringenin. The naringenin is then converted to dihydrokaempferol (DHK) by flavanone 3hydroxylase $(\mathrm{F} 3 \mathrm{H})$, and the B-ring of DHK hydroxylated by the $\mathrm{P} 450$ enzymes flavonoid $3^{\prime}$-hydroxylase $\left(\mathrm{F} 3^{\prime} \mathrm{H}\right)$ and flavonoid $3^{\prime}, 5^{\prime}$-hydroxylase $\left(\mathrm{F}^{\prime} 5^{\prime} \mathrm{H}\right)$ leads to the synthesis of dihydroquercetin and dihydromyricetin, respectively. Subsequently, dihydroflavonol 4-reductase (DFR) and anthocyanidin synthase (ANS) are the key enzymes responsible for cyanidin and delphinidin. The synthesized anthocyanidins undergo several modifications by uridine diphosphate (UDP)-glucose:flavonoid glucosyltransferase and methyl transferase, resulting in stable anthocyanins. Additionally, the naringenin and dihydroflavonols can also be converted to flavones and flavonols, respectively, by the action of flavone synthase and flavonol synthase. The flavonoid biosynthetic pathway has been well studied in some terrestrial ornamental plants, such as Eustoma grandiflorum (Noda et al., 2004), Rhododendron ×pulchrum (Nakatsuka et al., 2008), Paeonia lactiflora (Zhao et al., 2012, 2016), and Viola $\times$ wittrockiana (Li et al., 2014). In contrast, information on flavonoid biosynthesis in the aquatic plant $N$. nucifera is very few, with only some studies done on the chromosomal localization of bronze 1 and bronze 2, isolation and tissuespecific expression analysis of $C H S$, as well as a comparative proteomic analysis between red and white cultivars at one stage before flower full opening (Deng et al., 2015; Diao et al., 2004; Dong et al., 2015). There has been no systematic research on the relationship between expression patterns of flavonoid biosynthetic genes and pigment accumulation in diverse flower color cultivars of $N$. nucifera throughout flower development, and molecular mechanisms involved in pigmentation process, especially anthocyanin biosynthesis, have not been fully elucidated yet until now. In this study, to better understand mechanisms underlying flower coloration in $N$. nucifera, we measured color indices across four cultivars with different

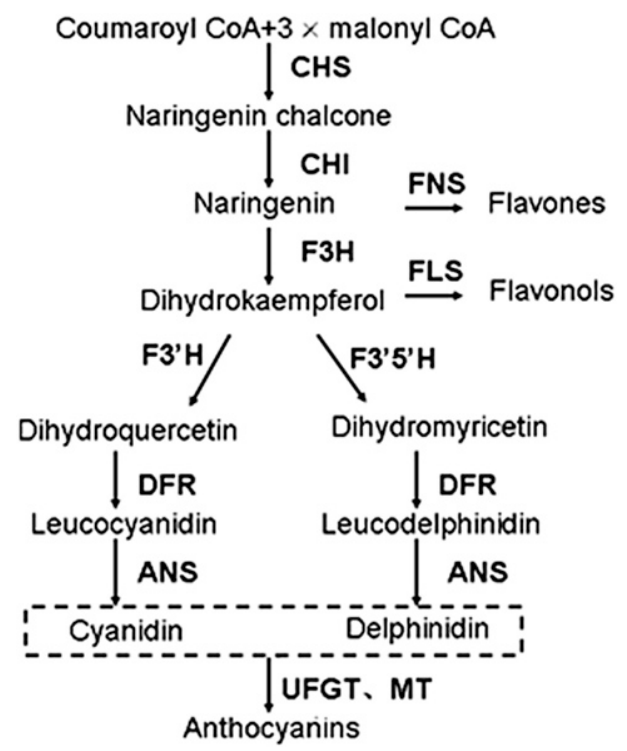

Fig. 1. The putative flavonoid biosynthetic pathway in Nelumbo nucifera; chalcone synthase (CHS), chalcone isomerase (CHI), flavanone 3-hydroxylase $(\mathrm{F} 3 \mathrm{H})$, flavonoid $3^{\prime}$-hydroxylase $\left(\mathrm{F} 3^{\prime} \mathrm{H}\right)$, flavonoid $3^{\prime}, 5^{\prime}$-hydroxylase $\left(\mathrm{F}^{\prime} 5^{\prime} \mathrm{H}\right)$, flavone synthase (FNS), flavonol synthase (FLS), dihydroflavonol 4-reductase (DFR), anthocyanidin synthase (ANS), UDP-glucose:flavonoid glucosyltransferase (UFGT), methyl transferase (MT). flower colors, isolated cDNA clones of seven flavonoid biosynthetic genes, and investigated their expression patterns together with the accumulation of total flavonoids and anthocyanins during flower development.

\section{Materials and Methods}

Plant materials. Four $N$. nucifera cultivars with diverse flower colors, including ZGH (red), XHF (pink), MLQS (yellow), and ZFCY (white), were collected in Nanjing Yileen Garden Co., Jiangsu Province, China. Each cultivar was planted in the water pool $(10 \times 8 \mathrm{~m})$ with 30 rhizomes under the same cultivation conditions in Apr. 2015, and grown under natural day/night conditions with an average temperature $30 / 20{ }^{\circ} \mathrm{C}$ (day/ night). Middle-layer petals were separated from these cultivars at four different developmental stages (Fig. 2): bud stage (S1), initial opening stage (S2), full opening stage (S3), and wilting stage (S4) (Wang and Zhang, 2005), and sampled for determination of total flavonoids and anthocyanins as well as RNA extraction. In addition, leaf, petal, stamen, and pistil samples for spatial gene expression analysis were collected from $\mathrm{ZGH}$ at the full opening stage. All samples were collected at $1000 \mathrm{HR}$, immediately frozen in liquid nitrogen after measurement of flower color indices, and then stored at $-80{ }^{\circ} \mathrm{C}$ for further use.

MeAsurement OF FLOWER COLOR INDICES. Flower color indices of middle layer petals were measured with a chroma meter (CR-400; Konica Minolta Sensing, Osaka, Japan) using three color parameters including $L^{*}, a^{*}$, and $b^{*}$ values in daylight conditions. In the uniform color space, $L^{*}$ represents the lightness, $a^{*}$ represents the ratio of red and green, and $b^{*}$ represents the ratio of yellow and blue (Voss, 1992). Chroma $\left[C^{*}=\left(a^{* 2}+b^{* 2}\right)^{1 / 2}\right]$ was calculated based on the method reported by Voss (1992). Color indices were determined on three replicates (an average value of five measurements of one flower for each replicate).

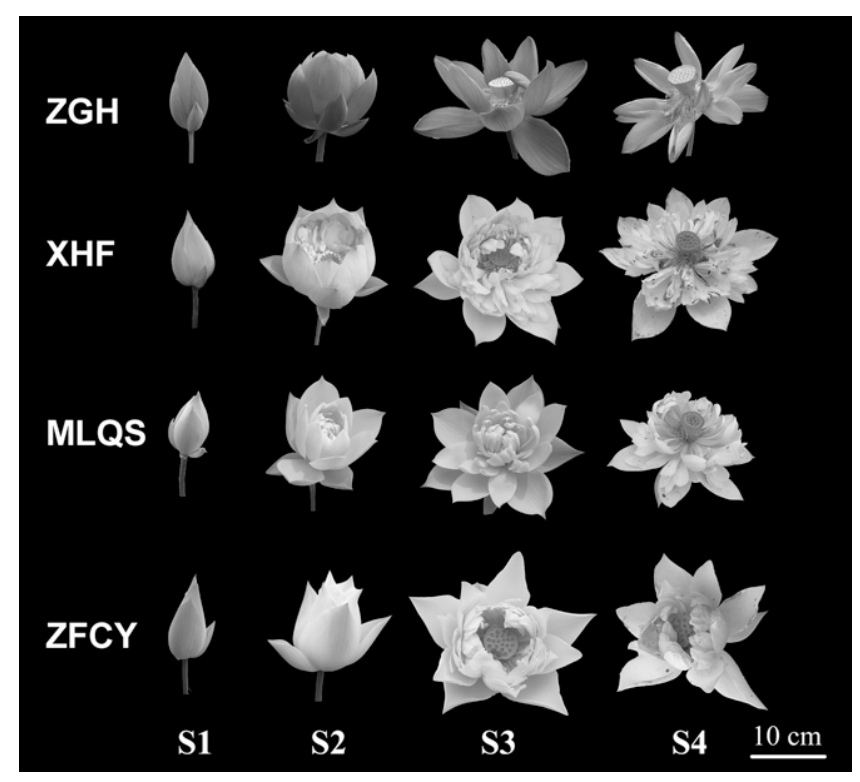

Fig. 2. Flowers of Nelumbo nucifera cultivars Zhongguohongbeijing (ZGH), Xinghuafen (XHF), Molingqiuse (MLQS), and Zhufengcuiying (ZFCY) at different developmental stages: bud stage (S1), initial opening stage (S2), full opening stage (S3), and wilting stage (S4). 
DETERMINATION OF FLAVONOID AND ANTHOCYANIN CONTENTS. Flavonoid contents were determined according to the method described by Jia et al. (1999) and Mitić et al. (2012) with some modifications. In brief, fresh petal samples $(0.4 \mathrm{~g})$ were extracted in $6 \mathrm{~mL}$ of $0.1 \%(\mathrm{v} / \mathrm{v}) \mathrm{HCl}$ methanol solution with gentle shaking overnight at $4{ }^{\circ} \mathrm{C}$. Next, $0.1 \mathrm{~mL}$ extractions was mixed with $2 \mathrm{~mL}$ of distilled water and, subsequently, with 0.15 $\mathrm{mL}$ of $5 \% \mathrm{NaNO}_{2}$. After reaction for $5 \mathrm{~min}$ at room temperature, the mixture was added by $0.75 \mathrm{~mL}$ of $2 \% \mathrm{AlCl}_{3}$ and further incubated for $5 \mathrm{~min}$. Then $1 \mathrm{~mL}$ of $1 \mathrm{M} \mathrm{NaOH}$ was added and a final volume was made up to $5 \mathrm{~mL}$. The absorbance of the mixture was immediately measured at $510 \mathrm{~nm}$. Flavonoid contents were determined by a catechin standard curve and expressed as catechin equivalent on a fresh weight (FW) basis.

Anthocyanin contents were measured by a modified $\mathrm{pH}$ differential method (Niu et al., 2010; Wrolstand et al., 1982). Fresh petal samples $(0.4 \mathrm{~g})$ were extracted with $5 \mathrm{~mL}$ of $0.05 \%$ $\mathrm{HCl}$ methanol solution at $4{ }^{\circ} \mathrm{C}$ for $12 \mathrm{~h}$. After centrifugation at $10,000 g_{n}$ for $20 \mathrm{~min}$, the supernatant was removed and the residue was re-extracted in $4 \mathrm{~mL}$ of the $\mathrm{HCl}$ methanol solution. The combined supernatants were collected and made up to a final volume of $10 \mathrm{~mL}$. Then $1 \mathrm{~mL}$ supernatant and $4 \mathrm{~mL}$ of either $0.4 \mathrm{M} \mathrm{KCl}-\mathrm{HCl}$ buffer $\left(\mathrm{pH} \mathrm{1.0)}\right.$ ) or $0.4 \mathrm{M}$ citric acid- $\mathrm{Na}_{2}$ $\mathrm{HPO}_{4}$ buffer ( $\mathrm{pH} 4.5$ ) were mixed. Following 20 min of extraction at room temperature, the absorbance of both solutions was measured at 510 and $700 \mathrm{~nm}$. Anthocyanin contents were expressed as cyanidin-3-O-glucoside equivalent on an $\mathrm{FW}$ basis. All determinations were performed with three replicates.

Total RNA EXTRACTION AND CDNA syNthesis. Total RNA was extracted from different tissues of $N$. nucifera according to the cetyltrimethylammonium bromide (CTAB)-LiCl method reported by Zhang et al. (2013). One gram of frozen tissue was ground in liquid nitrogen using a mortar and pestle, and quickly transferred to $1 \mathrm{~mL}$ extraction buffer prewarmed to $65{ }^{\circ} \mathrm{C}$ for $5 \mathrm{~min}$. The extraction buffer contained 2\% (w/v) CTAB, $2 \%(\mathrm{w} / \mathrm{v})$ polyvinylpyrrolidone, $100 \mathrm{~mm}$ Tris- $\mathrm{HCl}$ (pH 8.0), $25 \mathrm{~mm}$ ethylenediaminetetraacetic acid $(\mathrm{pH}$ 8.0), $2 \mathrm{M} \mathrm{NaCl}$, and 2\% $\beta$-mercaptoethanol. The RNA was extracted by adding an equal volume of chloroform, and then precipitated by $12 \mathrm{M}$ $\mathrm{LiCl}$ overnight at $-20^{\circ} \mathrm{C}$. The RNA pellet was resuspended in $500 \mu \mathrm{L}$ diethylpyrocarbonate (DEPC)-treated water and extracted by adding chloroform. Then, two volumes of ethanol were added to the collected upper phase. The pellet was collected after incubating $-80{ }^{\circ} \mathrm{C}$ for $2 \mathrm{~h}$, and washed twice with $75 \%$ ethanol, and then dissolved in $30 \mu \mathrm{L}$ DEPC-treated water after evaporation of ethanol. Total RNA was digested with RNase-free DNase I (TaKaRa, Kusatsu, Japan) to remove the residual genomic DNA. The quantity and quality of RNA were assessed using a bioanalyzer system (2100 Bioanalyzer; Agilent Technologies, Santa Clara, CA). The first-stand cDNA was synthesized from $1 \mu \mathrm{g}$ DNA-free RNA using a PrimeScript ${ }^{\circledR}$ RT reagent Kit (TaKaRa) according to the manufacturer's instructions.

CONFIRMATION OF THE OPEN READING FRAME SEQUENCES OF FLAVONOID BIOSYNTHETIC GENES AND SEQUENCE ANALYSIS. In previous studies, the whole genome of $N$. nucifera as well as its flower-bud transcriptome library was sequenced (Ming et al., 2013; Wang et al., 2013a; Zhang et al., 2014a). Based on the related genome-based data and related unigene sequences, cDNA clones of seven flavonoid biosynthetic structural genes including $\mathrm{NnCHS}, \mathrm{NnCHI}, \mathrm{NnF} 3 \mathrm{H}, \mathrm{NnF} 3^{\prime} \mathrm{H}$, NnF3'5'H, NnDFR, and $N n A N S$ were obtained from petals of $\mathrm{ZGH}$ with PCR, and the open reading frame (ORF) sequences of these genes were further confirmed with the designed primers (Supplemental Table 1). The PCR program was carried out at $94^{\circ} \mathrm{C}$ for $5 \mathrm{~min}$, followed by 30 cycles of $30 \mathrm{~s}$ at $94{ }^{\circ} \mathrm{C}, 30$ $\mathrm{s}$ at 60 to $64{ }^{\circ} \mathrm{C}, 1 \mathrm{~min}$ at $72{ }^{\circ} \mathrm{C}$, and $7 \mathrm{~min}$ at $72^{\circ} \mathrm{C}$ for each gene as shown in Supplemental Table 1. All amplified products were cloned into pMD19-T vector (TaKaRa), and then putative positive clones were identified by PCR with RV-M and M1347 sequencing primers before they were sequenced by Nanjing Springen Biotech Co. (Nanjing, China).

Comparisons of the nucleotide and predicted amino acid sequences were performed using the BLAST program, and the conserved domains present in the deduced protein sequences were identified with Conserved Domain Search Service at the National Center for Biotechnology Information (Altschul et al., 1990; Marchler-Bauer et al., 2011). Phylogenetic analysis was

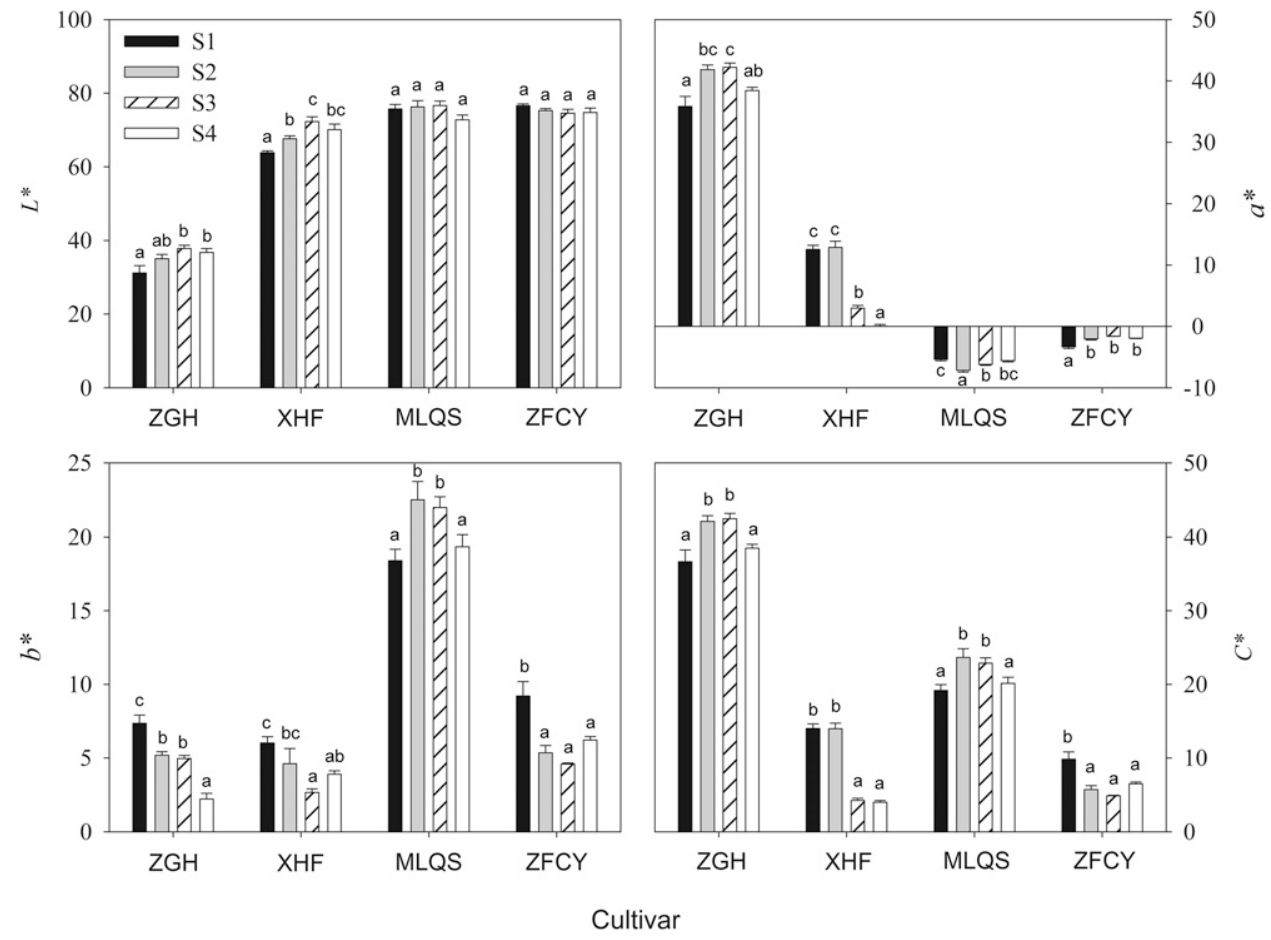

Fig. 3. Changes of flower color indices of Nelumbo nucifera cultivars Zhongguohongbeijing (ZGH), Xinghuafen (XHF), Molingqiuse (MLQS), and Zhufengcuiying (ZFCY) at different developmental stages: bud stage (S1), initial opening stage (S2), full opening stage (S3), and wilting stage (S4). Data are presented as mean with SE of three replications. Different lowercase letters indicate significant differences among developmental stages in the same cultivar using Duncan's multiple range test at $P<0.05$. 
carried out based on neighbor-joining model with 1000 bootstrap replications by MEGA version 4.0 (Tamura et al., 2007).

Gene EXPRESSION ANALysis. Expression levels of seven flavonoid biosynthetic structural genes were analyzed using real-time quantitative PCR (qRT-PCR) on a Mastercycler ep realplex instrument (Eppendorf, Hamburg, Germany). The specific primer sets for individual genes used for qRT-PCR are listed in Supplemental Table 2, and gene specificity test of all primer sets was performed as described by Wang et al. (2013b). qRT-PCR reactions were carried out using a $20-\mu \mathrm{L}$ reaction mixture comprising $10 \mu \mathrm{L}$ of SYBR ${ }^{\circledR}$ Premix Ex Taq ${ }^{\mathrm{TM}}$ (TaKaRa), $0.4 \mu \mathrm{L}$ of each primer $(10 \mu \mathrm{M}), 2 \mu \mathrm{L}$ of 10 -fold diluted cDNA, and 7.2 $\mu \mathrm{L}$ of PCR-grade water. The qRT-PCR program began with $30 \mathrm{~s}$ at $95^{\circ} \mathrm{C}$, followed by 40 cycles of $95^{\circ} \mathrm{C}$ for $5 \mathrm{~s}, 55^{\circ} \mathrm{C}$ for $30 \mathrm{~s}$, and $72^{\circ} \mathrm{C}$ for $30 \mathrm{~s}$, and completed with a melting curve analysis to determine the specificity of the amplification reaction. All qRT-PCR reactions were performed with three biological replicates, and no-template controls for each primer set were included in each run. The transcript abundance of each target gene was normalized to the genometric averaging of two carefully selected reference genes, $N$. nucifera action and elongation factor 1-alpha (EFla), and relative transcript levels were presented as mean with standard errors.

Statistical Analysis. Data were analyzed with variance and significant differences were compared by the Duncan's multiple range test at the level of $P<0.05$, using SPSS software (version 17.0; IBM Corp., Armonk, NY).

\section{Results}

FlOwER COLOR INDiCES. The differences in flower colors among four tested $N$. nucifera cultivars expressed as $L^{*}, a^{*}, b^{*}$, and $C^{*}$ are shown in Fig. 3. During flower development, $L^{*}$ values slightly increased in $\mathrm{ZGH}$ and XHF, and they showed little changes in other two cultivars. With regard to $a^{*}$, the values were highest in $\mathrm{ZGH}$, where they increased during early flower opening process with relatively high values of about 42 at $\mathrm{S} 2$ and $\mathrm{S} 3$, and then markedly decreased with flower wilting. In $\mathrm{XHF}, a^{*}$ values were reduced continuously from $\approx 12$ to almost undetectable levels throughout flower development, whereas in other two cultivars, $a^{*}$ values were at nearly constant and negligible levels. For $b^{*}$, their $b^{*}$ values were highest in MLQS, with values rising at early flower opening stages and subsequent declining. In contrast, $b^{*}$ values in other cultivars presented a downward trend basically along with flower development. $C^{*}$ values in ZGH and MLQS showed an initial rapid increase before a drop at later stages, but they continuously decreased in other two cultivars.

All these indices revealed that flower color trends were consistent with the visual results. As flower development proceeded, the flower color of ZGH and MLQS visibly deepened before a color fading, whereas the color of XHF and ZFCY gradually faded.

ACCumulation of Flavonoids AND ANTHOCYANINS DURING FLOWER DEVELOPMENT. As far as total flavonoids were concerned, the contents in MLQS were the highest, though they showed a similar declining trend before the later increase over the period of flower development in four cultivars (Fig. 4A). For anthocyanins, they drastically accumulated in $\mathrm{ZGH}$, whose contents increased with flower opening, reached the maximal values (1.46
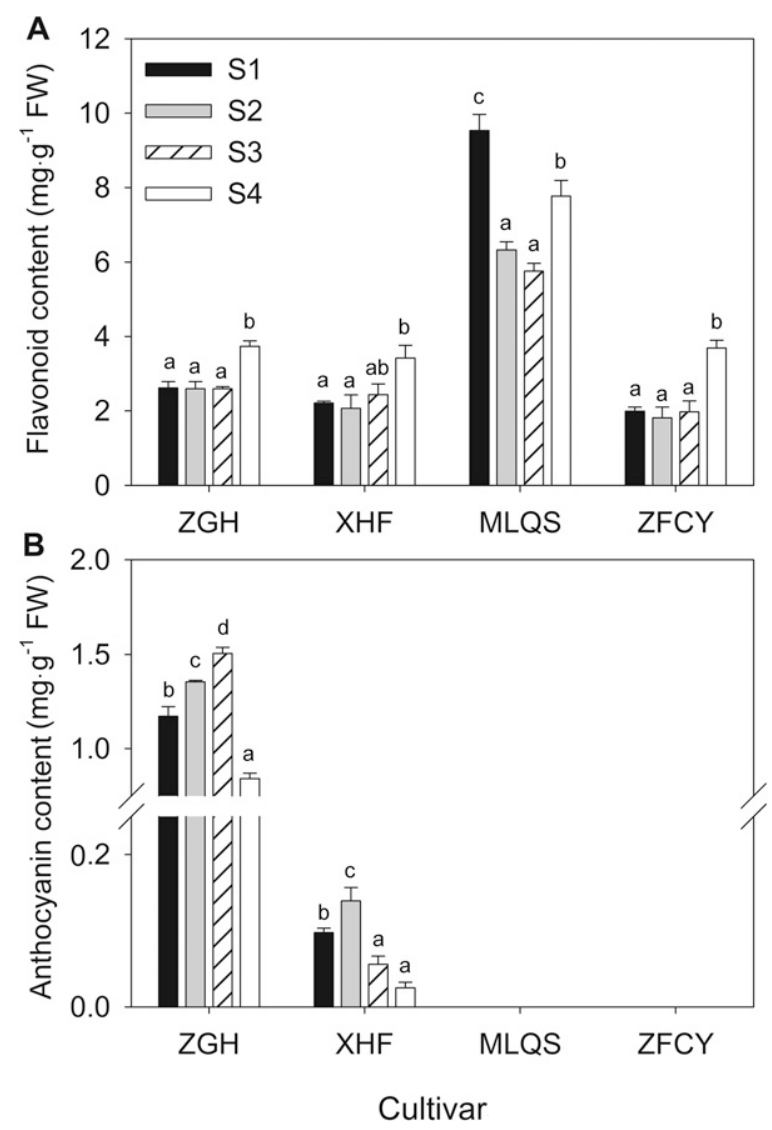

Fig. 4. The contents of total flavonoids (A) and anthocyanins (B) in Nelumbo nucifera cultivars Zhongguohongbeijing ( $\mathrm{ZGH}$ ), Xinghuafen (XHF), Molingqiuse (MLQS), and Zhufengcuiying (ZFCY) at different developmental stages: bud stage (S1), initial opening stage (S2), full opening stage (S3), and wilting stage (S4). Data are presented as mean with SE of three replications. Different lowercase letters indicate significant differences among developmental stages in the same cultivar using Duncan's multiple range test at $P<0.05$.

$\left.\mathrm{mg} \cdot \mathrm{g}^{-1} \mathrm{FW}\right)$ at S3, and thereafter sharply dropped until flowers wilted (Fig. 4B). Anthocyanin contents in XHF highly accumulated during early flower opening process with the peak at S2, and subsequently decreased to low levels. The anthocyanin accumulation in $\mathrm{ZGH}$ exhibited $\approx 10$-fold higher than that in $\mathrm{XHF}$. In contrast, the contents of anthocyanins were below detection limits in petals of MLQS and ZFCY.

ISOLATION AND SEQUENCE ANALYSIS OF FLAVONOID BIOSYNTHETIC STRUCTURAL GENES. In the present study, cDNA clones of seven flavonoid biosynthetic structural genes including $\mathrm{NnCHS}, \mathrm{NnCHI}, \mathrm{NnF} 3 \mathrm{H}, \mathrm{NnF} 3^{\prime} H, \mathrm{NnF}^{\prime} 5^{\prime} H, \mathrm{NnDFR}$, and $N n A N S$ were isolated from $Z$ GH. These cDNA sequences have been submitted to GenBank under accession numbers KX176839-KX176845. Among them, NnCHS had an ORF sequence of 1170 base pairs (bp), and encoded a 389-amino acid protein. A BLAST analysis showed that this protein shared 99\% identity with CHS from another $N$. nucifera cultivar Taikonglian, which had been deposited in GenBank under accession number ADD74167 (Dong et al., 2015). The putative ORF sequence of $\mathrm{NnCHI}$ was $630 \mathrm{bp}$ in length, encoding a 209amino acid protein. $N n F 3 H$ cDNA contained an ORF of $996 \mathrm{bp}$, encoding 331 amino acid residues. $N n F 3^{\prime} H$ had an ORF of 1542 bp, encoding 513 amino acids, whereas $N n F 3^{\prime} 5^{\prime} H$ had 
a 1524-bp ORF encoding 507 amino acids. The ORF for $N n D F R$ was 1029 bp, encoding 342 amino acids, and for NnANS was 1080 bp encoding 359 amino acids. The molecular mass of each putative protein was $42.58,48.58,37.73,56.42$, $56.37,38.56$, and $40.36 \mathrm{kDa}$, and the isoelectric point (pI) was $6.24,5.04,5.32,8.56,9.39,5.59$, and 5.75, respectively. Sequence comparison showed that deduced amino acid sequences of these genes shared high identities with related proteins from other species (Table 1).

Phylogenic analysis of each isolated gene with corresponding genes from other species based on predicted amino acid sequences revealed that each structural gene belonged to the corresponding clusters (Fig. 5). Among them, $N n F 3 H$ and $N n A N S$ belonged to the same cluster, whereas $N n F 3^{\prime} H$ and $N n F 3^{\prime} 5^{\prime} H$ belonged to another expected cluster.

EXPRESSION ANALYSIS OF FLAVONOID BIOSYNTHETIC STRUCTURAL GENES DURING FLOWER DEVELOPMENT. Comparing temporal gene expression patterns between tested $N$. nucifera cultivars, higher expression of seven isolated flavonoid biosynthetic structural genes was observed in $\mathrm{ZGH}$ than in other cultivars overall (Fig. 6). As far as single gene was concerned, $\mathrm{NnCHS}$ and $\mathrm{NnCHI}$ shared a similar temporal expression pattern and were relatively strongly expressed at bud stage (S1) compared with other later developmental stages, especially in cultivars which accumulated a certain amount of total flavonoids but none or less anthocyanins. $\mathrm{NnF} 3 \mathrm{H}$ messenger RNA (mRNA) showed the highest abundance among seven flavonoid biosynthetic structural genes, and also abundantly expressed at S1, though its expression patterns exhibited obvious variation across different color cultivars. For $N n F 3^{\prime} H$, its transcript gradually rose till the maximal values were reached at S3 and then declined with wilting in $\mathrm{ZGH}$, whereas it continuously increased over the period of flower development in MLQS and ZFCY. Interestingly, $N n F 3^{\prime} H$ expression was almost below detection limits throughout flower development in XHF. Transcripts of $N n F 3^{\prime} 5^{\prime} H, N n D F R$, and $N n A N S$ displayed similar changing patterns to anthocyanin accumulation in diverse cultivars: in $\mathrm{ZGH}$, their expression levels increased fluctuantly, peaked at S3 with the highest anthocyanin accumulation, and then sharply decreased; in XHF, their transcripts were more abundant at S1 when relatively high anthocyanins were accumulated, and followed by a rapid drop to faint mRNA signals, although the peak time of gene expression was not coincident with that of anthocyanin contents; meanwhile, in the other two cultivars lacking anthocyanins, the three transcripts exhibited very low abundance or no significant difference between any two developmental stages. For example, $N n D F R$ and $N n A N S$ transcripts were barely detectable in MLQS and $\mathrm{ZFCY}$, respectively. It was worth mentioning that $N n \mathrm{F3}^{\prime} 5^{\prime} H$ showed the lowest expression level compared with other six structural genes.

EXPRESSION ANALYSIS OF FLAVONOID BIOSYNTHETIC STRUCTURAL GENES IN DIFFERENT TISSUES. Spatial expression patterns of all isolated flavonoid biosynthetic structural genes were also determined, and results showed that their expression levels were tissue specific in four different tissues of $\mathrm{ZGH}$ (Fig. 7). NnCHS exhibited the highest transcript abundance in petals, moderate expression level in pistils and stamens, and trace level in leaves. Unlike $\mathrm{NnCHS}$, both $\mathrm{NnCHI}$ and $N n F 3^{\prime} 5^{\prime} H$ were strongly expressed in leaves but weakly in floral tissues, in spite of low $N n F 3^{\prime} 5^{\prime} H$ mRNA level in all tested tissues. Transcripts of the remaining four genes including $N n F 3 H, N n F 3^{\prime} H, N n D F R$, and $N n A N S$ were more abundant in petals than those in other tissues, especially $N n F 3 H$ and $N n A N S$, whose expression levels in petals were 148.6 and 107.7 times as much as those in the second most highly expressed tissue, respectively. As a whole, most flavonoid biosynthetic structural genes were preferentially and highly expressed in floral tissues of $N$. nucifera, rather than the vegetative tissue.
Table 1. Comparison of deduced amino acid sequences of flavonoid biosynthetic genes from Nelumbo nucifera with other species.

\begin{tabular}{|c|c|c|c|}
\hline Gene & Species & Accession no. & Identities (\%) \\
\hline \multirow[t]{3}{*}{ Chalcone synthase (CHS) } & N. nucifera & ADD74167 & 99 \\
\hline & Gossypium hirsutum & ABS52573 & 94 \\
\hline & Vitis vinifera & AEP17003 & 93 \\
\hline \multirow{3}{*}{ Chalcone isomerase (CHI) } & Hibiscus cannabinus & AIC73814 & 81 \\
\hline & G. hirsutum & ADG27840 & 81 \\
\hline & Lonicera japonica & AGE10598 & 79 \\
\hline \multirow[t]{3}{*}{ Flavanone 3-hydroxylase $(\mathrm{F3H})$} & Glycine soja & KHN35581 & 72 \\
\hline & Morus notabilis & XP_010091357 & 71 \\
\hline & Medicago truncatula & XP_003601080 & 70 \\
\hline \multirow[t]{3}{*}{ Flavonoid $3^{\prime}$-hydroxylase $\left(F 3^{\prime} H\right)$} & Camellia nitidissima & ADZ28515 & 81 \\
\hline & V. vinifera & ALP48438 & 80 \\
\hline & Camellia sinensis & ALO62102 & 80 \\
\hline \multirow[t]{3}{*}{ Flavonoid $3^{\prime}, 5^{\prime}$-hydroxylase $\left(F^{\prime} 3^{\prime} 5^{\prime} H\right)$} & G. hirsutum & AAP31058 & 83 \\
\hline & $V$. vinifera & $\mathrm{ABC} 72066$ & 82 \\
\hline & Ribes nigrum & AGI16385 & 81 \\
\hline \multirow[t]{3}{*}{ Dihydroflavonol 4-reductase (DFR) } & Vitis bellula & AFG28176 & 67 \\
\hline & $\begin{array}{c}\text { Chrysanthemum } \\
\text { morifolium }\end{array}$ & AEN69001 & 66 \\
\hline & Dahlia pinnata & ACO50430 & 66 \\
\hline \multirow[t]{3}{*}{ Anthocyanidin synthase (ANS) } & Morus alba & AEN55613 & 83 \\
\hline & $V$. vinifera & ABV82967 & 83 \\
\hline & Theobroma cacao & ADD51356 & 82 \\
\hline
\end{tabular}

\section{Discussion}

Flavonoids play a vital role in flower color formation and diversity in many ornamental plants (Tanaka et al., 2005, 2008; Zhao and Tao, 2015). Flavonoid biosynthesis is manipulated by a series of structural and regulatory genes, among which, transcriptional levels of structural genes are directly associated with flavonoid biosynthesis and accumulation (Collette et al., 2004; Nakatsuka et al., 2005; Zhao et al., 2012, 2015a). In this study, seven cDNA clones of structural genes in the flavonoid biosynthetic pathway including $\mathrm{NnCHS}$, $\mathrm{NnCHI}, \mathrm{NnF} 3 \mathrm{H}, \mathrm{NnF3} H, \mathrm{NnF}^{\prime} 5^{\prime} H$, $N n D F R$, and NnANS were successfully isolated from petals of $N$. nucifera ZGH. Sequence analysis indicated that deduced amino acid sequences of these genes shared $66 \%$ to $99 \%$ identities with each corresponding protein reported previously, and had typical structures. 


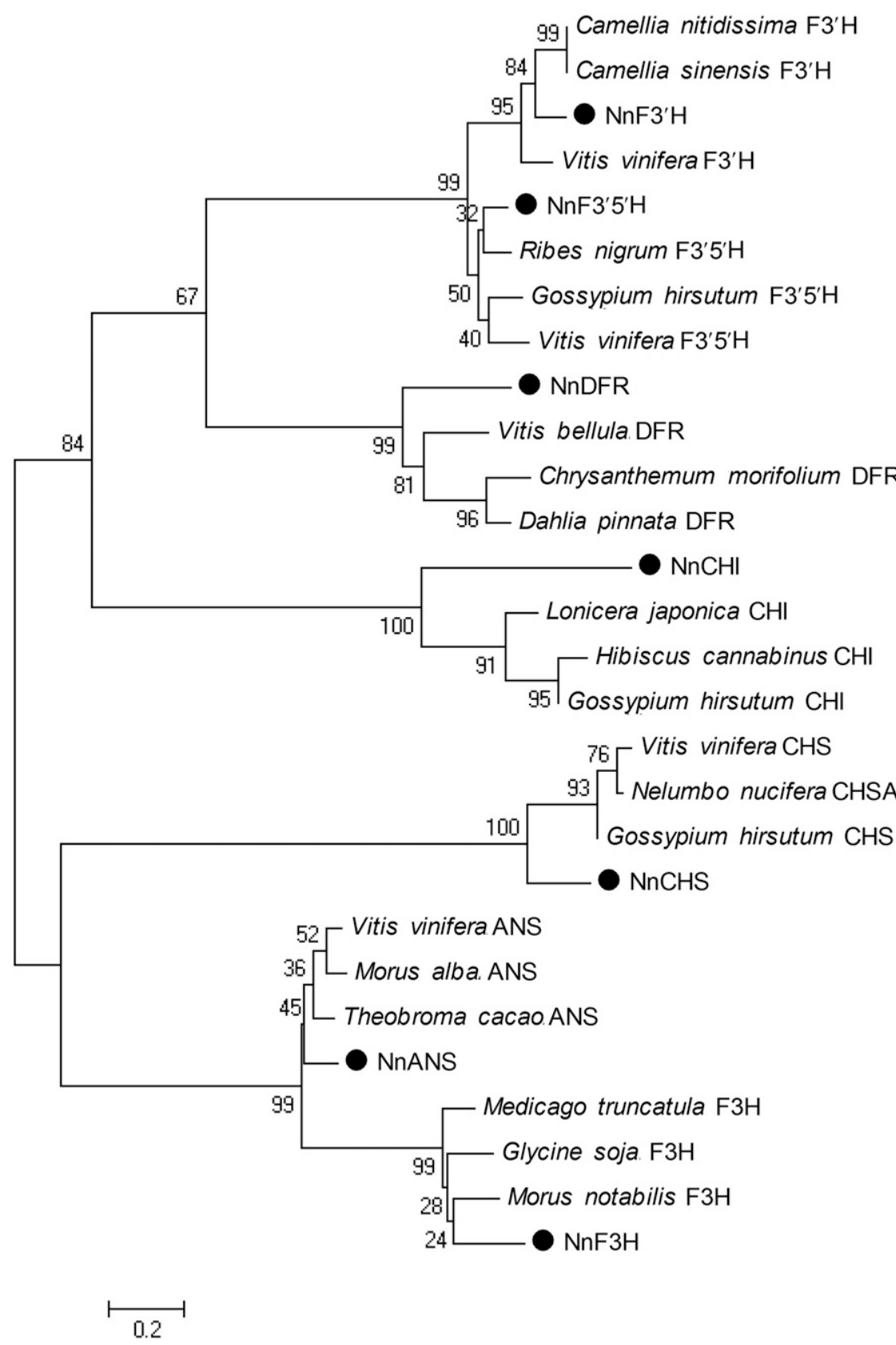

Fig. 5. Phylogenic analysis of chalcone synthase (CHS), chalcone isomerase (CHI), flavanone 3-hydroxylase $(\mathrm{F} 3 \mathrm{H})$, flavonoid $3^{\prime}$-hydroxylase $\left(\mathrm{F} 3^{\prime} \mathrm{H}\right)$, flavonoid 3',5'-hydroxylase $\left(\mathrm{F} 3{ }^{\prime} 5^{\prime} \mathrm{H}\right)$, dihydroflavonol 4-reductase (DFR), and anthocyanidin synthase (ANS) in various plant species calculated on the basis of amino acid sequences. The phylogenic tree was generated using MEGA program by the neighbor-joining method (Tamura et al., 2007). Protein sequences used in the phylogenies with accession numbers were shown in Table 1. Proteins encoded by genes isolated in this study were highlighted by black circles. The scale below means 0.2 amino acid substitutions per site.

NnCHS was shown to have conservative amino acid sequences of CHS-like domain, including the active site, substrate specificity domain, malonyl-CoA binding motif, and CHS signature sequence (Samappito et al., 2002; Sun et al., 2015). It is worth noting that this obtained deduced amino acid sequence shared high (99\%) identity but not exactly the same with previous CHS sequences of $N$. nucifera deposited in GenBank, which is probably due to cultivar difference (Dong et al., 2015). The obtained NnCHI sequence here had the conserved domain of Chalcone superfamily, which also exists in CHI from other species (Cheng et al., 2011; Yuan et al., 2013). NnF3H and NnANS, both belonging to an expected cluster in the phylogenic analysis, had conserved domains of the 2-oxoglutarate and Fe (II)-dependent oxygenase superfamily (Lukacin and Britsch, 1997), including two histidine residues and an aspartate residue for Fe (II) ligation, and an arginine residue and a serine residue involved in 2-oxoglutarate binding. $\mathrm{NnF}^{\prime} \mathrm{H}$ and $\mathrm{NnF}^{\prime} 5^{\prime} \mathrm{H}$ contained several characteristic motifs of amino acid sequences conserved in the cytochrome P450 superfamily (Chapple, 1998), such as the proline-rich region, the oxygen-binding pocket, and the hemebinding domain. A conserved nicotinamide adenine dinucleotide phosphate-binding region in DFR superfamily (Lacombe et al., 1997) was also found in NnDFR obtained in our study. DFR is known to catalyze the conversion of dihydroflavonols to their respective leucoanthocyanidins in many species; however, certain types of DFR are reported to lack the ability to convert DHK to leucopelargonidin. For example, petunia DFR cannot effectively reduce DHK to produce pelargonidin-based anthocyanin (Forkmann and Ruhnau, 1987), because of a substitution of asparagine to aspartate at amino acid residue 134 (Beld et al., 1989; Johnson et al., 2001). Similarly, in NnDFR here, amino acid residue 135 (corresponding 134 residue of petunia) was also not an asparagine but a leucine, which might be responsible for the lack of pelargonidin accumulation previously reported in N. nucifera (Deng et al., 2013; Yang et al., 2009). Taken together, these data strongly suggested that our isolated cDNA clones putatively encode corresponding enzymes indeed.

Structural genes involved in the flavonoid biosynthetic pathway could be divided into two categories: early biosynthetic genes required for the synthesis of precursors of multiple flavonoids, including $\mathrm{CHS}, \mathrm{CHI}$, and $F 3 H$, and late biosynthetic genes specific for anthocyanin biosynthesis, such as DFR and ANS (Pelletier et al., 1997; Tornielli et al., 2009). In this study, temporal expression patterns of seven isolated structural genes were monitored in petals of different $N$. nucifera cultivars. Transcripts of early biosynthetic genes $\mathrm{NnCHS}, \mathrm{NnCHI}$, and $\mathrm{NnF} 3 \mathrm{H}$ were abundant at bud stage (S1), especially in cultivars with a certain amount of total flavonoids but none or less anthocyanins. It has also been reported that massive expression of early biosynthetic genes occurred at early flower developmental stage of different color cultivars in Senecio cruentus (Hu et al., 2009), Chrysanthemum morifolium (Chen et al., 2010), and Paeonia suffruticosa (Zhao et al., 2015a). Since CHS, CHI, and F3H are early enzymes required 

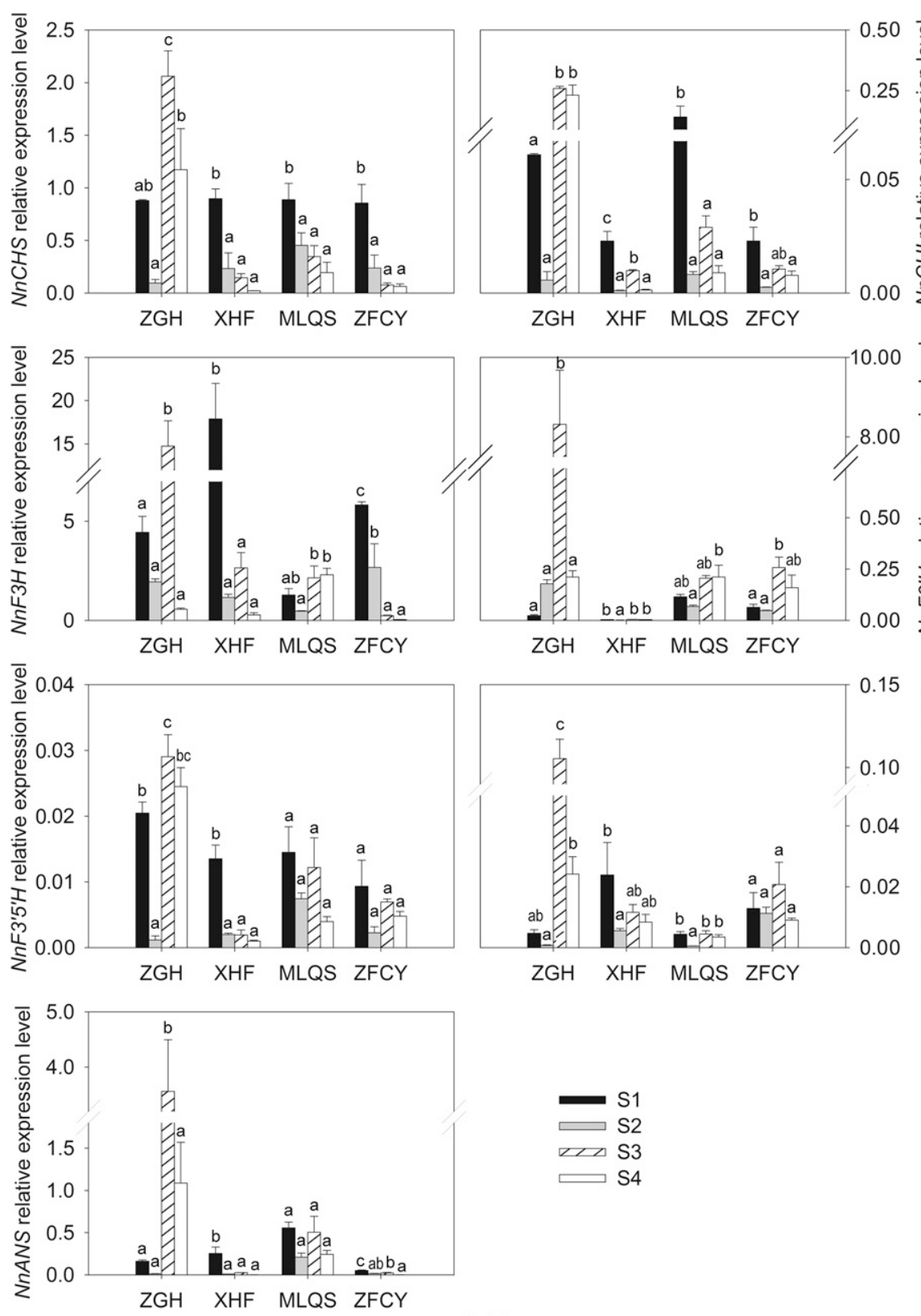

\section{Cultivar}

Fig. 6. Expression analysis of flavonoid biosynthetic genes in Nelumbo nucifera cultivars Zhongguohongbeijing (ZGH), Xinghuafen (XHF), Molingqiuse (MLQS), and Zhufengcuiying (ZFCY) at different developmental stages [bud stage (S1), initial opening stage (S2), full opening stage (S3), wilting stage (S4)] by real-time quantitative PCR. Data are presented as mean with SE of three replications. Different lowercase letters indicate significant differences among developmental stages in the same cultivar using Duncan's multiple range test at $P<0.05$.

for total flavonoid biosynthesis which is constituted by many branch synthesis pathways besides anthocyanins, high transcripts of $\mathrm{NnCHS}, \mathrm{NnCHI}$, and $\mathrm{NnF} 3 \mathrm{H}$ at $\mathrm{S} 1$ here were supposed to directly enhance the synthesis of other flavonoids, probably kaempferol and isorhamnetin (Deng et al., 2013). Noticeably, among these different color cultivars at S1, the strongest expression of $\mathrm{NnCHI}$ in MLQS accompanying highest flavonoid accumulation, was in line with the finding in yellowflowered C. morifolium (Chen et al., 2010), which possibly caused abundant anthoxanthin synthesis and displayed yellow.

According to expression patterns of late biosynthetic genes, $N n F 3^{\prime} H, N n F 3^{\prime} 5^{\prime} H, N n D F R$, and $N n A N S$ were expressed in

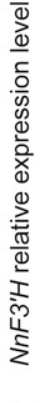

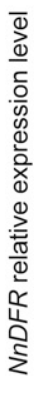

a manner basically consistent with the pattern of anthocyanin accumulation in $\mathrm{ZGH}$, increasing to reach the maximum values at flower fullopening stage and then declining with flower wilting. Moreover, higher expression levels of these genes were detected in this red cultivar that had the highest anthocyanin contents than in other cultivars overall, similar to the results of C. morifolium (Chen et al., 2010), $P$. lactiflora (Zhao et al., 2012), and $P$. suffruticosa (Zhao et al., 2015a), suggesting the involvement of these late biosynthetic genes in colored anthocyanin synthesis. However, $N n F 35^{\prime} H$ transcript exhibited very low level compared with other genes during flower development of $N$. nucifera. As a result, despite a contribution of $N n F 35^{\prime} \mathrm{H}$ to color formation, $N n F 3 H, N n D F R$, and NnANS appeared to play a more significant role. Recent studies have demonstrated that overexpression of a heterologous $A N S$ or DFR leaded to a visible increase in red color intensity of petals, concomitant with increased anthocyanin contents (Chu et al., 2015; Liu et al., 2013). Compared with high transcript abundance in $\mathrm{ZGH}$, the expression level of $N n F 3^{\prime} H$, which may be important for the synthesis of cyanidin and peonidin-based anthocyanins, was rather low and even below detectable limits in XHF. It is possible that minor cyanidin derivatives were synthesized in petals of the pink cultivar, which was in accordance with previous findings that pink cultivars of $N$. nucifera contained much less Cy3G and Pn3G than red ones (Deng et al., 2013). NnF3'5'H, NnDFR, and NnANS transcripts were abundant at $\mathrm{S} 1$ and sharply decreased during the following flower developmental stages in the pink cultivar here, which was not always coincident with the anthocyanin contents. This result had some similarities with the report in pinkflowered C. morifolium that the peak time of structural genes expression preceded that of anthocyanin accumulation (Han et al., 2012), suggesting that the effects of high expression of these late biosynthetic genes on enhancing anthocyanin accumulation in XHF would last for a certain time. Although no anthocyanins were detected in MLQS and ZFCY, some late biosynthetic genes, for example $N n F 3^{\prime} H$, were expressed in all stages of the two cultivars, suggesting that the lack of anthocyanins could not be due to any blockage of their expression. It is worth noting that negligible expression levels 

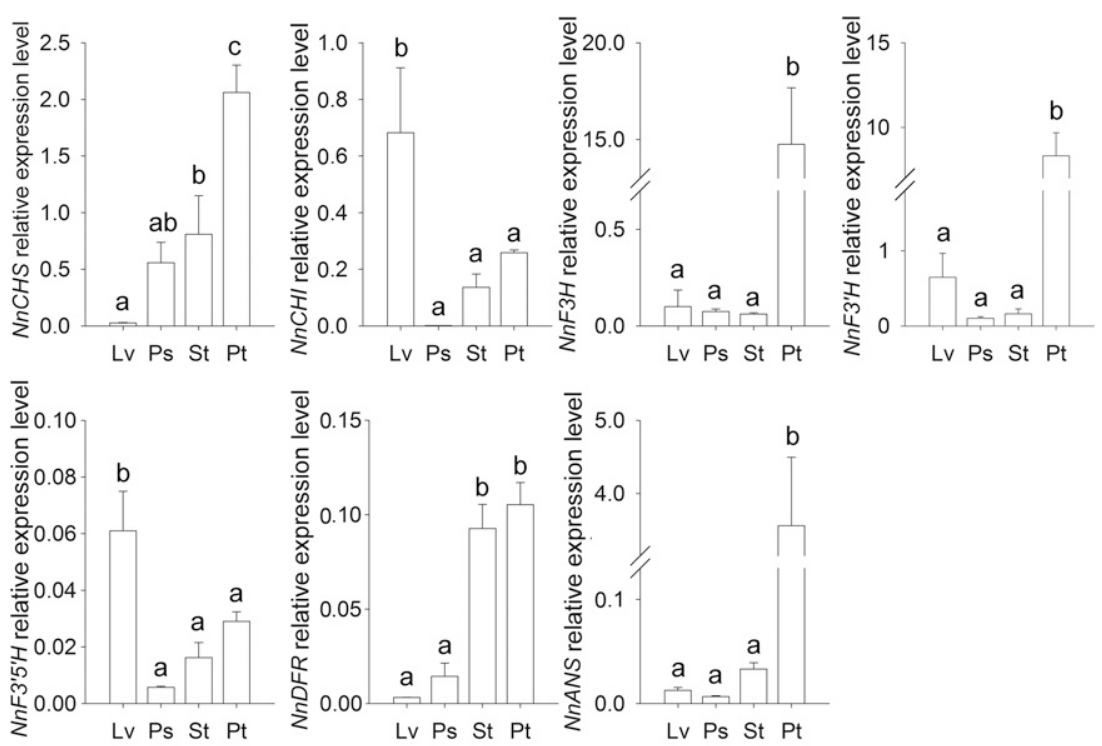

Tissue

Fig. 7. Expression analysis of flavonoid biosynthetic genes in leaves (Lv), pistils (Ps), stamens (St), and petals $(\mathrm{Pt})$ of Nelumbo nucifera cultivar Zhongguohongbeijing $(\mathrm{ZGH})$ at the full opening stage by real-time quantitative polymerase chain reaction (qRT-PCR). Data are presented as mean with SE of three replications. Different lowercase letters indicate significant differences among developmental stages in the same cultivar using Duncan's multiple range test at $P<0.05$.

of $N n D F R$ and $N n A N S$ were detected in the yellow and white cultivars, respectively. Since $D F R$ and $A N S$ are late biosynthetic genes that only participate in the conversion of colorless dihydroflavonols to colored anthocyanidins (Grotewold, 2006; Tanaka et al., 2008), this phenomenon could explain the absence of anthocyanin pigment in the two cultivars. Similarly, in Punica granatum, a high expression of $P g A N S$ was detected only in red- but not white-fruited cultivars (Zhao et al., 2015b); Weak or no DFR expression in the yellow cultivar of Allium cepa (Kim et al., 2004), C. morifolium (Chen et al., 2010), or P. lactiflora (Zhao et al., 2012) appeared to be the bottleneck preventing anthocyanin synthesis and resulted in yellow color.

For spatial expression in our study, seven isolated flavonoid biosynthetic structural gene transcripts were found to be detected in all tested tissues of $\mathrm{ZGH}$, even in the vegetative tissue. Similar expression patterns have been seen in $R$. $\times$ pulchrum (Nakatsuka et al., 2008), P. lactiflora (Zhao et al., 2012), and $P$. suffruticosa (Zhang et al., 2014b). Most structural genes here were expressed higher in floral tissues, especially in petals, than those in leaves. For example, $\mathrm{NnCHS}$ was abundantly expressed in all tested floral tissues, which confirmed the previous report in another cultivar of $N$. nucifera that $N n C H S A$ showed the highest expression level in red flower but lowest level in leaves (Dong et al., 2015). Together with downstream strong expression of $N n F 3 H, N n F 3^{\prime} H, N n D F R$, and $N n A N S$ in petals, sequentially a great quantity of anthocyanins was produced in flowers of $\mathrm{ZGH}$. In contrast, $\mathrm{NnCHI}$ and $\mathrm{NnF}^{\prime} \mathrm{5}^{\prime} \mathrm{H}$ exhibited low expression in floral tissues, but they accumulated higher transcript levels in leaves that contained more flavones and flavonols. The spatial expression pattern of $\mathrm{NnCHI}$ might be due to its involvement in regulating colorless anthoxanthin biosynthesis, just as TfCHI in Tulipa fosteriana (Yuan et al., 2013) and PsCHI in P. suffruticosa (Zhang et al., 2014b; Zhou et al., 2014). As $\mathrm{F}^{\prime} 5^{\prime} \mathrm{H}$ is the enzyme indispensable for the synthesis of some flavonoids, such as anthocyanins (delphinidin, petunidin, and malvidin) and flavonols (myricetin) (Seitz et al., 2016; Tanaka et al., 2008; Zhao and Tao, 2015), higher expression of $N n F 3^{\prime} 5^{\prime} \mathrm{H}$ in leaves here would generate myricetin derivates, which have been previously found in lotus leaves (Chen et al., 2012).

In conclusion, pigment profiles and expression patterns of seven flavonoid biosynthetic structural genes have been characterized across four $N$. nucifera cultivars with different flower colors in this study. Early biosynthetic genes showed high transcript abundances at the early developmental stage, implying their involvement in flavone and flavonol derivatives in N. nucifera. Moreover, expression patterns of late biosynthetic genes, especially $N n D F R$ and $N n A N S$, were in general consistent with the anthocyanin accumulation, suggesting that the regulation of these genes expression might directly change anthocyanin contents, which would in turn affect the final flower color of $N$. nucifera. These findings will advance our understanding of the molecular mechanisms underlying flower coloration in $N$. nucifera, and provide a theoretical basis to improve its flower colors via genetic engineering.

\section{Literature Cited}

Altschul, S.F., W. Gish, W. Miller, E.W. Myers, and D.J. Lipman. 1990. Basic local alignment search tool. J. Mol. Biol. 215:403-410. Beld, M., C. Martin, H. Huits, A.R. Stuitje, and A.G. Gerats. 1989. Flavonoid synthesis in Petunia hybrida: Partial characterization of dihydroflavonol-4-reductase genes. Plant Mol. Biol. 3:491-502.

Chapple, C. 1998. Molecular-genetic analysis of plant cytochrome P450-dependent monooxygenase. Annu. Rev. Plant Biol. 49:311343.

Chen, S., B.H. Wu, J.B. Fang, Y.L. Liu, H.H. Zhang, L.C. Fang, L. Guan, and S.H. Li. 2012. Analysis of flavonoids from lotus (Nelumbo nucifera) leaves using high performance liquid chromatography/ photodiode array detector tandem electrospray ionization mass spectrometry and an extraction method optimized by orthogonal design. J. Chromatography 1227:145-153.

Chen, S.M., X.R. Zhu, F.D. Chen, H.L. Luo, G.S. Lv, W.M. Fang, and Z. Zhang. 2010. Expression profiles of anthocyanin biosynthetic genes in chrysanthemum cultivars with different flower colors. Acta Botanica Boreali-Occidentalia Sinica 30:453-458.

Cheng, H., L. Li, S. Cheng, F. Cao, Y. Wang, and H. Yuan. 2011. Molecular cloning and function assay of a chalcone isomerase gene (GbCHI) from Ginkgo biloba. Plant Cell Rpt. 30:49-62.

Chu, Y.X., H.R. Chen, A.Z. Wu, R. Cai, and J.S. Pan. 2015. Expression analysis of dihydroflavonol 4-reductase genes in Petunia hybrida. Genet. Mol. Res. 14:5010-5021.

Collette, V.E., P.E. Jameson, K.E. Schwinn, P. Umaharan, and K.M. Davies. 2004. Temporal and spatial expression of flavonoid biosynthetic genes in flowers of Anthurium andraeanum. Physiol. Plant. 122:297-304.

Deng, J., S. Chen, X. Yin, K. Wang, Y. Liu, S. Li, and P. Yang. 2013. Systematic qualitative and quantitative assessment of anthocyanins, flavones and flavonols in the petals of 108 lotus (Nelumbo nucifera) cultivars. Food Chem. 139:307-312. 
Deng, J., Z. Fu, S. Chen, R.N. Damaris, K. Wang, T. Li, and P. Yang. 2015. Proteomic and epigenetic analyses of lotus (Nelumbo nucifera) petals between red and white cultivars. Plant Cell Physiol. 56:15461555.

Diao, Y., J.Y. Liu, M.Q. Zhou, and Z.L. Hu. 2004. Chromosomal localization of anthocyanin biosynthetic genes $b z 1, b z 2$ in lotus. J. Wuhan Bot. Res. 22:380-384.

Dong, C., A.Q. Yu, M.L. Wang, X.W. Zheng, Y. Diao, K.Q. Xie, M.Q. Zhou, and Z.L. Hu. 2015. Identification and characterization of chalcone synthase cDNAs (NnCHS) from Nelumbo nucifera. Cell. Mol. Biol. 61:112-117.

Forkmann, G. and B. Ruhnau. 1987. Distinct substrate specificity of dihydroflavonol 4-reductase from flowers of Petunia hybrida. Zeitschrift Für Naturforschung C 42:1146-1148.

Grotewold, E. 2006. The genetics and biochemistry of floral pigments. Annu. Rev. Plant Biol. 57:761-780.

Han, K.T., L. Zhao, X.J. Tang, K. Hu, and S.L. Dai. 2012. The relationship between the expression of key genes in anthocyanin biosynthesis and the color of chrysanthemum. Acta Hort. Sinica 39:516-524.

Hu, K., L. Meng, K.T. Han, Y. Sun, and S.L. Dai. 2009. Isolation and expression analysis of key genes involved in anthocyanin biosynthesis of cineraria. Acta Hort. Sinica 36:1013-1022.

Jia, Z., M. Tang, and J. Wu. 1999. The determination of flavonoid contents in mulberry and their scavenging effects on superoxide radicals. Food Chem. 64:555-559.

Johnson, E.T., S. Ryu, H. Yi, B. Shin, H. Cheong, and G. Choi. 2001. Alteration of a single amino acid changes the substrate specificity of dihydroflavonol 4-reductase. Plant J. 25:325-333.

Kim, S., M.L. Binzel, S. Park, K.S. Yoo, and L.M. Pike. 2004. Inactivation of $D F R$ (dihydroflavonol 4-reductase) gene transcription results in blockage of anthocyanin production in yellow onions (Allium cepa). Mol. Breed. 14:253-263.

Lacombe, E., S. Hawkins, J.V. Doorsselaere, J. Piquemal, D. Goffner, O. Poeydomenge, A.M. Boudet, and J. Grima-Pettenati. 1997. Cinnamoyl CoA reductase, the first committed enzyme of the lignin branch biosynthetic pathway: Cloning, expression and phylogenetic relationships. Plant J. 11:429-441.

Li, Q., J. Wang, H.Y. Sun, and X. Shang. 2014. Flower color patterning in pansy (Viola $\times$ wittrockiana Gams.) is caused by the differential expression of three genes from the anthocyanin pathway in acyanic and cyanic flower areas. Plant Physiol. Biochem. 84:134-141.

Liu, Y., Z. Shi, S. Maximova, M.J. Payne, and M.J. Guiltinan. 2013. Proanthocyanidin synthesis in Theobroma cacao: Genes encoding anthocyanidin synthase, anthocyanidin reductase, and leucoanthocyanidin reductase. BMC Plant Biol. 13:202.

Lukacin, R. and L. Britsch. 1997. Identification of strictly conserved histidine and arginine residues as part of the active site in Petunia hybrida flavone 3beta-hydroxylase. Eur. J. Biochem. 249:748-757.

Marchler-Bauer, A., S. Lu, J.B. Anderson, F. Chitsaz, M.K. Derbyshire, C. DeWeese-Scott, J.H. Fong, L.Y. Geer, R.C. Geer, N.R. Gonzales, M. Gwadz, D.I. Hurwitz, J.D. Jackson, Z. Ke, C.J. Lanczycki, F. Lu, G.H. Marchler, M. Mullokandov, M.V. Omelchenko, C.L. Robertson, J.S. Song, N. Thanki, R.A. Yamashita, D. Zhang, N. Zhang, C. Zheng, and S.H. Bryant. 2011. CDD: A conserved domain database for the functional annotation of proteins. Nucleic Acids Res. 39:D225D229.

Ming, R., R. VanBuren, Y. Liu, M. Yang, Y. Han, L. Li, Q. Zhang, M. Kim, M.C. Schatz, M. Campbell, J. Li, J.E. Bowers, H. Tang, E. Lyons, A.A. Ferguson, G. Narzisi, D.R. Nelson, C.E. Blaby-Haas, A.R. Gschwend, Y. Jiao, J.P. Der, F. Zeng, J. Han, X.J. Min, K.A. Hudson, R. Singh, A.K. Grennan, S.J. Karpowicz, J.R. Watling, K. Ito, S.A. Robinson, M.E. Hudson, Q. Yu, T.C. Mockler, A. Carroll, Y. Zheng, R. Sunkar, R. Jia, N. Chen, J. Arro, C.M. Wai, E. Wafula, A. Spence, Y. Han, L. Xu, J. Zhang, R. Peery, M.J. Haus, W. Xiong, J.A. Walsh, J. Wu, M. Wang, Y.J. Zhu, R.E. Paull, A.B. Britt, C. Du, S.R. Downie, M.A. Schuler, T.P. Michael, S.P. Long, D.R. Ort, J.W. Schopf, D.R. Gang, N. Jiang, M. Yandel, C.W. dePamphilis, S.S.
Merchant, A.H. Paterson, B.B. Buchanan, S. Li, and J. Shen-Miller. 2013. Genome of the long-living sacred lotus (Nelumbo nucifera Gaertn.). Genome Biol. 14:R41.

Mitić, M.N., J.M. Souquet, M.V. Obradović, and S.S. Mitić. 2012. Phytochemical profiles and antioxidant activities of Serbian table and wine grapes. Food Sci. Biotechnol. 21:1619-1626.

Nakatsuka, A., D. Mizuta, Y. Kii, I. Miyajima, and N. Kobayashi. 2008. Isolation and expression analysis of flavonoid biosynthesis genes in evergreen azalea. Scientia Hort. 118:314-320.

Nakatsuka, T., M. Nishihara, K. Mishiba, and S. Yamamura. 2005. Temporal expression of flavonoid biosynthesis-related genes regulates flower pigmentation in gentian plants. Plant Sci. 168:13091318 .

Nishihara, M. and T. Nakatsuka. 2011. Genetic engineering of flavonoid pigments to modify flower color in floricultural plants. Biotechnol. Lett. 33:433-441.

Niu, S.S., C.J. Xu, W.S. Zhang, B. Zhang, X. Li, K.L. Wang, I.B. Ferguson, A.C. Allan, and K.S. Chen. 2010. Coordinated regulation of anthocyanin biosynthesis in chinese bayberry (Myrica rubra) fruit by a R2R3 MYB transcription factor. Planta 231:887-899.

Noda, N., Y. Kanno, N. Katoa, K. Kazuma, and M. Suzuk. 2004. Regulation of gene expression involved in flavonol and anthocyanin biosynthesis during petal development in lisianthus (Eustoma grandiflorum). Physiol. Plant. 122:305-313.

Pelletier, M.K., J.R. Murrell, and B.W. Shirley. 1997. Characterization of flavonol synthase and leucoanthocyanidin dioxygenase genes in Arabidopsis. Further evidence for differential regulation of "early" and "late" genes. Plant Physiol. 113:1437-1445.

Qi, A.T. 1989. Physiology and biochemistry of flower color. China For. Publ. House, Beijing, China.

Samappito, S., J. Page, J. Schmidt, W. De-Eknamkul, and T.M. Kutchan. 2002. Molecular characterization of root-specific chalcone synthases from Cassia alata. Planta 216:64-71.

Seitz, C., C. Eder, B. Deiml, S. Kellner, S. Martens, and G. Forkmann. 2006. Cloning, functional identification and sequence analysis of flavonoid $3^{\prime}$-hydroxylase and flavonoid $3^{\prime}, 5^{\prime}$-hydroxylase cDNAs reveals independent evolution of flavonoid $3^{\prime}, 5^{\prime}$-hydroxylase in the asteraceae family. Plant Mol. Biol. 61:365-381.

Sun, W., X. Meng, L. Liang, W. Jiang, Y. Huang, J. He, H. Hu, J. Almqvist, and X. Gao. 2015. Molecular and biochemical analysis of chalcone synthase from Freesia hybrid in flavonoid biosynthetic pathway. PLoS One 10:e0119054.

Tamura, K., J. Dudley, M. Nei, and S. Kumar. 2007. MEGA4: Molecular evolutionary genetics analysis (MEGA) software version 4.0. Mol. Biol. Evol. 24:1596-1599.

Tanaka, Y., N. Sasaki, and A. Ohmiya. 2008. Biosynthesis of plant pigments: Anthocyanins, betalains and carotenoids. Plant J. 54:733749.

Tanaka, Y., Y. Katsumoto, F. Brugliera, and J. Mason. 2005. Genetic engineering in floriculture. Plant Cell Tissue Organ Cult. 80:1-24.

Tornielli, G., R. Koes, and F. Quattrocchio. 2009. The genetics of flower color, p. 269-299. In: T. Gerats and J. Strommer (eds.). Petunia. Springer, New York, NY.

Voss, D.H. 1992. Relating colorimeter measurement of plant color to the Royal Horticultural Society Colour Chart. HortScience 27:12561260.

Wang, Q.C. and X.Y. Zhang. 2005. Lotus flower cultivars in China. China For. Publ. House, Beijing, China.

Wang, Y., C. Zhang, P. Jia, X. Wang, W. Wang, and L. Dong. 2013 b. Isolation and expression analysis of three EIN3-like genes in tree peony (Paeonia suffruticosa). Plant Cell Tissue Organ Cult. 112:181-190.

Wang, Y., G. Fan, Y. Liu, F. Sun, C. Shi, X. Liu, J. Peng, W. Chen, X. Huang, S. Cheng, Y. Liu, X. Liang, H. Zhu, C. Bian, L. Zhong, T. Lv, H. Dong, W. Liu, X. Zhong, J. Chen, Z. Quan, Z. Wang, B. Tan, C. Lin, F. Mu, X. Xu, Y. Ding, A. Guo, J. Wang, and W. Ke. 2013a. The sacred lotus genome provides insights into the evolution of flowering plants. Plant J. 76:557-567. 
Winkel-Shirley, B. 2001. Flavonoid biosynthesis. A colorful model for genetics, biochemistry, cell biology, and biotechnology. Plant Physiol. 126:485-493.

Wrolstand, R.E., J.D. Culbertson, C.J. Cornwell, and L. Mattick. 1982. Detection of adulteration in blackberry juice concentrates and wines. J. Assoc. Off. Anal. Chem. 6:1417-1423.

Yang, R.Z., X.L. Wei, F. Gao, L.S. Wang, H.J. Zhanga, Y.J. Xu, C.H. Li, Y.X. Ge, J.J. Zhang, and J. Zhang. 2009. Simultaneous analysis of anthocyanins and flavonols in petals of lotus (Nelumbo) cultivars by high-performance liquid chromatography-photodiode array detection/ electrospray ionization mass spectrometry. J. Chromatography 1216:106-112.

Yuan, Y., X. Ma, Y. Shi, and D. Tang. 2013. Isolation and expression analysis of six putative structural genes involved in anthocyanin biosynthesis in Tulipa fosteriana. Scientia Hort. 153:93-102.

Zhang, C., W. Wang, Y. Wang, S. Gao, D. Du, J. Fu, and L. Dong. 2014b. Anthocyanin biosynthesis and accumulation in developing flowers of tree peony (Paeonia suffruticosa) 'Luoyang Hong'. Postharvest Biol. Technol. 97:11-22.

Zhang, W., D. Tian, X. Huang, Y. Xu, H. Mo, Y. Liu, J. Meng, and D. Zhang. 2014a. Characterization of flower-bud transcriptome and development of genic SSR markers in asian lotus (Nelumbo nucifera Gaertn.). PLoS One 9:e112223.

Zhang, X.Y. 2011. New lotus flower cultivars in China. China For. Publ. House, Beijing, China.
Zhang, Y.J., X.Y. Hao, Z.S. Liang, W.D. Ke, and H.B. Guo. 2013. Efficient isolation of high-quality RNA from lotus Nelumbo nucifera ssp nucifera tissues. Genet. Mol. Res. 12:223-229.

Zhao, D. and J. Tao. 2015. Recent advances on the development and regulation of flower color in ornamental plants. Front. Plant Sci. $6: 261$.

Zhao, D., J. Tao, C. Han, and J. Ge. 2012. Flower color diversity revealed by differential expression of flavonoid biosynthetic genes and flavonoid accumulation in herbaceous peony (Paeonia lactiflora Pall.). Mol. Biol. Rpt. 39:11263-11275.

Zhao, D., M. Wei, D. Liu, and J. Tao. 2016. Anatomical and biochemical analysis reveal the role of anthocyanins in flower coloration of herbaceous peony. Plant Physiol. Biochem. 102:97-106.

Zhao, D., W. Tang, Z. Hao, and J. Tao. 2015a. Identification of flavonoids and expression of flavonoid biosynthetic genes in two coloured tree peony flowers. Biochem. Biophys. Res. Commun. 459:450-456.

Zhao, X., Z. Yuan, L. Feng, and Y. Fang. 2015b. Cloning and expression of anthocyanin biosynthetic genes in red and white pomegranate. J. Plant Res. 128:687-696.

Zhou, L., Y. Wang, L. Ren, Q. Shi, B. Zheng, K. Miao, and X. Guo. 2014. Overexpression of $P s-C H I 1$, a homologue of the chalcone isomerase gene from tree peony (Paeonia suffruticosa), reduces the intensity of flower pigmentation in transgenic tobacco. Plant Cell Tissue Organ Cult. 116:285-295. 
Supplemental Table 1. Primers used for flavonoid biosynthetic genes isolation in Nelumbo nucifera.

\begin{tabular}{|c|c|c|c|c|}
\hline \multirow[b]{2}{*}{ Gene } & \multirow[b]{2}{*}{ Primer } & \multirow[b]{2}{*}{ Oligonucleotide sequence $\left(5^{\prime}-3^{\prime}\right)$} & \multicolumn{2}{|c|}{ Annealing condition } \\
\hline & & & Temperature $\left({ }^{\circ} \mathrm{C}\right)$ & Product size (base pairs) \\
\hline \multirow[t]{2}{*}{$\overline{\mathrm{NnCHS}}$} & CHS-F & ATGGTGACCGTGGAAGACA & 64 & 1,170 \\
\hline & CHS-R & CTAGGCAGCGATACTGTGAA & & \\
\hline & CHI-R & ATTCACTTGGATAACAGGTC & & \\
\hline \multirow[t]{2}{*}{$\mathrm{NnF} 3 \mathrm{H}$} & F3H-F & ATGGAGGTAGAGAGGGTG & 60 & 1,001 \\
\hline & F3H-R & CTCCCTTACTGTGGTAGTT & & \\
\hline & F3'H-R & CTAGGACGAGGCACGATA & & \\
\hline \multirow[t]{2}{*}{$N n F 3^{\prime} 5^{\prime} H$} & F35H-F & ATGGCTTTCGACATAGTCCTTGC & 64 & 1,524 \\
\hline & F35H-R & TCAAGCGGCATAAGCGGTAG & & \\
\hline \multirow[t]{2}{*}{$N n D F R$} & DFR-F & CCTTCATCCTGTTGACCAT & 62 & 1,046 \\
\hline & DFR-R & CTACTCCATCTCCTTGTCT & & \\
\hline NnANS & ANS-F & ATGGCTCAACCACTTGCAGTTG & 64 & 1,102 \\
\hline
\end{tabular}

Supplemental Table 2. Sequences of primers for real-time quantitative polymerase chain reaction (qRT-PCR) analyses.

\begin{tabular}{lllr}
\hline Gene & \multicolumn{1}{c}{ Forward primer $\left(5^{\prime}-3^{\prime}\right)$} & \multicolumn{1}{c}{ Reverse primer $\left(5^{\prime}-3^{\prime}\right)$} & Product size $($ base pairs $)$ \\
\hline$N n C H S$ & ATTGACGGACACCTGAGAG & AGCACACGAGCACTTGAC & 269 \\
$N n C H I$ & GTTACGGAGATGCTGAAG & AGGTCTGAGAGGTTGTG & 92 \\
$N n F 3 H$ & GGAGGTAACAGAGGAGTA & AGTATGGTGAGAGCAGAC & 222 \\
$N n F 3^{\prime} H$ & TGATGTCCGAGGTAACG & GTGGCAGTCAAGAGGTG & 105 \\
$N n F 3^{\prime} 5^{\prime} H$ & GATTGCTTGGATGGACTTG & CCCTGTTGGCGTAGATTA & 158 \\
$N n D F R$ & AGGAGCATCTGGTTACATC & CAGCCTTCCATAGAGTCAA & 158 \\
$N n A N S$ & GAAGTCGGTGGAGTAGAAG & CCTGGAACGCCTGCAGA & 160 \\
$N n A c t i n$ & GCGTTCTGCCGTCTTCTAAA & CCCTCTTGGATTGTGCCTC & 228 \\
$N n E F I a$ & GTGGACAAGAAGGACGCA & GGCATAGTAAACAACAGACC & 104 \\
\hline
\end{tabular}

